\title{
Exposure to violence and its relationship to mental health among young people in Palestine
}

Glenn Wagner, ${ }^{1}$ Peter Glick, ${ }^{1}$ Umaiyeh Khammash, ${ }^{2,3}$ Mohammed Shaheen, ${ }^{4}$ Ryan Brown, ${ }^{1}$ Prodyumna Goutam, ${ }^{1}$ Rita Karam, ${ }^{1}$ Sebastian Linnemayr, Salwa Massad ${ }^{3.5}$

${ }^{1}$ RAND Corporation, Santa Monica, California, United States of America (Correspondence to: Glenn Wagner: gwagner@rand.org). ${ }^{2} J u z o o r$ for Health and Social Development, Ramallah, Palestine. ${ }^{3}$ United Nations Relief and Works Agency for Palestine Refugees in the Near East (UNRWA), Jerusalem, Palestine. ${ }^{4}$ School of Public Health, Al Quds University, Abu-Dis, Palestine. ${ }^{5}$ Palestinian National Institute of Public Health, Ramallah, Palestine.

\begin{abstract}
Background: Exposure to violence is a significant risk factor for the development of psychopathology in young people. Research on the mental health consequences of violence exposure in youth has focused mostly on post-traumatic stress disorder, however, the association with depression and anxiety has also been established. As a result of the longstanding Israeli-Palestinian conflict, young Palestinians are vulnerable to exposure to various types of violence.
\end{abstract}

Aims: We examined psychiatric symptomatology and its relationship to direct and indirect forms of violence exposure.

Methods: A representative household survey of 2481 Palestinian youth was conducted in 2014. Self-report measures included psychiatric symptomatology (global distress, depression, anxiety) and violence exposure (personal victimization, witnessed, vicariously heard about).

Results: The proportion of elevated symptoms of global distress (46\%), depression (55\%), and (37\%) anxiety was high; $47 \%$ had been a personal victim, $71 \%$ had witnessed violence, and $69 \%$ had heard about violence experienced by someone close to them. In logistic regression analysis, controlling for other bivariate correlates, exposure to any violence event, as well as any of the 3 types of violence exposure, were independently associated with each of the 3 measures of elevated psychiatric symptomatology. Females were 4 times more likely to report elevated psychopathology, despite being less likely to experience each type of violence.

Conclusions: These findings suggest the need for services that cater to the mental health needs of youth in settings of high violence exposure, and that gender-specific strategies may be useful.

Keywords: depression, anxiety, violence exposure, youth, Palestine

Citation: Wagner G; Glick P; Khamma-sh U; Shaheen M; Brown R; Goutam P; et al. Exposure to violence and its relationship to mental health among young people in Palestine. East Mediterr Health J. 2020;26(2):189-197. https://doi.org/10.26719/2020.26.2.189

Received: 07/09/17; accepted: 20/05/18

Copyright (C) World Health Organization (WHO) 2020. Open Access. Some rights reserved. This work is available under the CC BY-NC-SA 3.0 IGO license (https://creativecommons.org/licenses/by-nc-sa/3.o/igo)

\section{Introduction}

Exposure to violence is a significant risk factor for the development of psychopathology in children and youth as it has been found to be related to aggression, academic difficulties and symptoms of post-traumatic stress, anxiety and depression (1). Protracted exposure to violence may lead young people to feel as though their safety and that of family and friends is constantly jeopardized (2). Violence exposure can take the form of personal victimization, as a witness to violence, or vicariously hearing about violence from others. While research on nonpolitical violence often makes these distinctions in considering impacts of violence on mental health (1), most research on political conflict has considered only aggregated violence exposure (3). Some research suggests that direct victimization has more detrimental effects on mental health than does the more prevalent witnessing of violence $(4,5)$, but there are nonetheless substantial negative effects of witnessing violence (6).

Research on the mental health consequences of violence exposure in youth, including in the Middle East (7), has focused mostly on post-traumatic stress disorder; however, the associations of violence exposure with depression and anxiety have also been established in the Region, including for the Palestinian territories (8). In a study of nearly 2000 14-17-year-olds in the West Bank and Gaza, children with greater exposure to conflict-related violence had greater post-traumatic distress and more somatic complaints, with girls having more somatic complaints than boys (9). In a study in Gaza that used ratings from parents and teachers of 350 kindergarten students, psychological resilience was negatively associated with exposure to traumatic events (10).

Other studies have found no or only modest correlations between violence exposure and psychiatric symptomatology in youth [see Barber \& Schluterman (11) for a review], which suggests the potential for resilience among youth exposed to ongoing violence. The risk and protective factor model of developmental psychopathology (12) highlights ecological and individual factors that either place young people at risk for psychopathology or promote resilience in the face of challenging circumstances. Protective factors help youth cope with the stress of ongoing violence by supporting 
self-worth, security of social relations, and sense of control (13). Gender differences have also been observed, with females often being exposed to less violence overall compared with males (14), but reporting more symptoms of psychological distress, in particular internalized symptoms (e.g. depression) (15).

Most studies of adolescents or youth in the Middle East have used school-based samples, which are limited by their focus on school-age children and exclusion of those no longer in school (and thus perhaps more vulnerable). In the present study, we used data from a unique representative household survey of Palestinian youth aged 15-24 years in the West Bank and East Jerusalem to examine the proportion of elevated psychiatric symptomatology, its relationship to various forms of violence exposure (personal victimization, witnessed, vicariously heard about), and identification of variables that may serve either to facilitate psychological resilience or exacerbate the risk of mental health problems.

The longstanding Israeli-Palestinian conflict has eluded resolution for decades, with severe negative implications for the well-being of Palestinian youth and others. While sustained large scale conflict breaks out only periodically, Palestinians in the West Bank, East Jerusalem, and Gaza face continuous risks to physical security and economic well-being. For residents of the West Bank, Israeli occupation has meant the ongoing threat of arrest, beatings, and in some instances home destruction. An ever-changing system of checkpoints and road closures significantly limits the physical mobility of Palestinians across the West Bank (16). Political demonstrations against the Occupation are a recurrent aspect of the conflict. Abusive treatment by the Palestinian Authority is also frequently reported (17). As a result, young Palestinians in the West Bank (as well as East Jerusalem) are vulnerable to exposure to various types of violence as well as to indirect conflict-related stressors such as economic hardship and constraints to mobility. It is important to understand the relation of these factors to mental health.

\section{Methods}

\section{Study design}

Details of the sampling and survey procedures are provided in a previous paper (18). Briefly, this cross-sectional study drew on the 2007 census to obtain a representative sample of youth aged 15-24 years living in the West Bank and East Jerusalem. A stratified 2-stage random sample was obtained in 208 clusters in urban, rural, and refugee camp locations for a total of 2481 youth, almost equally divided among males and females. The objective of the main study was to examine proportion and patterns of health risk behaviours in the context of exposure to trauma and violence.

Recruitment and data collection was carried out in April-July 2014. For minors (under 18 years), verbal parental informed consent was obtained to conduct the interview. Separate verbal consent was obtained from all youth. Oral rather than written consent was deemed appropriate to the survey content and environment as participants could provide sensitive information without a written record that could potentially identify them. A range of other precautions were taken to ensure participant confidentiality and anonymity. For example, interviewers were strictly instructed to ensure that the youth interview was carried out in a private room or other private area. Female youth were interviewed by females and male youth by males. The study procedures were approved by RAND's Human Subjects Protection Committee. Refusal to participate by parents/household head or youth was low, with $89 \%$ of selected participants granting consent to be interviewed.

\section{Measures}

The survey measures were administered in Arabic. Survey items were translated from English to Arabic using standard translation/back-translation methodology. All measures were developed by the study team unless otherwise noted or attribution is cited, and piloted prior to use with the study sample.

Demographic and background characteristics included sex, age, residence (urban, rural, refugee camp), work status, refugee status, school attendance, relationship status, religiosity, and whether or not the mother and father of the interviewee were living. Household resources were captured through ownership of various consumer durables such as a car, television and microwave which were used in a factor analysis to create a household wealth index (19), with mean zero and standard deviation 1.0.

Mental health was assessed with the 25-item Hopkins Symptoms Checklist (HSCL-25) (20), which is comprised of subscales measuring anxiety and depression (10 and 15 items respectively); the total 25 -item scale measures global distress. The HSCL-25 has high internal reliability (Cronbach's alpha $=0.95$ ) and 2-factor structure (21). Response options for each item range from o "not at all" to 3 "extremely"; responses within each of the 2 subscales, as well as the total scale, were summed and divided by the number of answered items to generate scores for depression, anxiety and global distress. Scores greater than 1.75 on each subscale (or total score) represent elevated symptomatology (22).

Exposure to violence was measured with a list of 11 events (Table 1), categorized into 3 types of violence exposure: personally experienced violence ( 5 events: e.g. beaten up or physically assaulted by soldiers or police, shot by rubber/plastic or real bullets, imprisoned or held by police or other authority); witnessed violence (4 events: e.g. witnessed shooting of close relative or friend, witnessed close relative's/friend's/neighbour's house closure or demolition); and vicarious or heard about violence ( 2 events: e.g. had a close relative or friend who was killed). Each item elicited a yes/no response as to whether the event was experienced, and if yes, the age 


\begin{tabular}{|c|c|c|c|c|}
\hline Characteristic & $\begin{array}{c}\text { Total } \\
(n=2481)\end{array}$ & $\begin{array}{c}\text { Males } \\
(n=1241)\end{array}$ & $\begin{array}{l}\text { Females } \\
(n=240)\end{array}$ & P-value \\
\hline \multicolumn{5}{|l|}{ Demographic and background characteristics } \\
\hline Mean age (years) & 19.1 & 18.9 & 19.2 & 0.002 \\
\hline Refugee (\%) & 26.0 & 25.4 & 26.5 & 0.518 \\
\hline Live in rural location (\%) & 26.9 & 26.9 & 26.9 & 0.989 \\
\hline Currently attending school (\%) & 63.0 & 60.2 & 64.8 & 0.020 \\
\hline Currently working (\%) & 18.5 & 31.0 & 6.0 & $<0.001$ \\
\hline Wealth (asset) index (\%) & 0.000 & 0.126 & -0.127 & $<0.001$ \\
\hline Married or engaged (\%) & 17.0 & 4.2 & 29.8 & $<0.001$ \\
\hline Very religious (\%) & 20.0 & 21.4 & 18.0 & 0.034 \\
\hline Father is alive (\%) & 93.7 & 94.0 & 93.4 & 0.505 \\
\hline Mother is alive (\%) & 98.5 & 99.1 & 97.8 & 0.009 \\
\hline Has someone to turn to for support (\%) & 83.0 & 82.4 & 83.8 & 0.228 \\
\hline Chance of having a good job by age $30(\%)$ & 48.3 & 54.7 & 41.9 & $<0.001$ \\
\hline Currently using tobacco $(\%)$ & 40.9 & 55.8 & 26.0 & $<0.001$ \\
\hline Has ever used alcohol (\%) & 11 & 13.8 & 7.3 & $<0.001$ \\
\hline Has attended more than 1 political demonstration or protest $(\%)$ & 25 & 29.7 & 20.7 & $<0.001$ \\
\hline \multicolumn{5}{|l|}{ Mental health } \\
\hline Global distress mean & 1.79 & 1.65 & 1.93 & $<0.001$ \\
\hline Elevated global distress (\%) & 45.7 & 33.2 & 58.2 & $<0.001$ \\
\hline Depression mean & 1.88 & 1.73 & 2.02 & $<0.001$ \\
\hline Elevated depression (\%) & 55.2 & 43.1 & 67.3 & $<0.001$ \\
\hline Anxiety mean & 1.67 & 1.54 & 1.80 & $<0.001$ \\
\hline Elevated anxiety (\%) & 37.0 & 26.5 & 47.7 & $<0.001$ \\
\hline \multicolumn{5}{|l|}{ Violence exposure } \\
\hline Sum of events experienced in lifetime & 2.90 & 3.42 & 2.33 & $<0.001$ \\
\hline Had any personal victimization events ${ }^{\mathrm{a}}(\%)$ & 46.7 & 61.6 & 31.9 & $<0.001$ \\
\hline Had any witnessed violence events ${ }^{\mathrm{b}}(\%)$ & 70.8 & 78.9 & 62.8 & $<0.001$ \\
\hline Had any vicarious violence events ${ }^{c}(\%)$ & 68.9 & 71.4 & 66.5 & 0.007 \\
\hline
\end{tabular}

"Share reporting "yes" to any of 5 events: been beaten up or physically assaulted, though not by police or soldiers; physically assaulted by soldiers or police; shot by rubber/plastic or real bullets; imprisoned or held by police or other authority; had house or family home closed or demolished by Israelis or others.

"Share reporting "yes" to any of 4 events: directly witnessed beating of close relative; directly witnessed killing of close relative or friend; witnessed shooting of close relative or friend by rubber/ plastic or real bullets; directly witnessed a close relative/friend's/neighbours' house closure or demolition

"Share reporting "yes" to any of 2 events: had a close relative or friend who was killed, though you did not witness it; had a close relative who was imprisoned or held.

at which it was last experienced was recorded. For each of the 3 violence types, as well as the scale as a whole, a dichotomous variable was created to represent whether any events of that type had been experienced.

The assessment also covered psychosocial characteristics. Social support was measured with a single yes/no item, "If you need help or have a problem or question about anything, is there a specific person that you can go to for help or support or an answer to the question"? Future outlook was measured by respondents' estimation of "the percent chance (o to 100\%) that you will have a good job by the time you are 30 years of age." Fatalism was measured with a 6-item scale adapted from a scale developed by Esparza (23), which has demonstrated good internal reliability (Cronbach's alpha $=0.76)$, test-retest reliability $(r=0.71)$, and construct validity. Respondents were asked to indicate their level of agreement with statements (e.g. What happens to me in the future mostly depends on me.) on a scale of 1 "strongly disagree" to 4 "strongly agree"; items framed against fatalism were reverse scored, and then the mean item score was calculated such that higher scores represent greater fatalism. To assess substance use, respondents were asked if they currently use tobacco (cigarettes and waterpipe) or use alcohol, and if they have ever taken an alcoholic drink (all using a yes/no format). Political activism was assessed by asking participants if they had ever attended a political demonstration, and if so, how many times in their lifetime. A binary variable was created to represent whether or not the participant was politically active, defined as having attended at least 2 demonstrations. 
Table 2 Bivariate correlates of elevated symptoms of global distress, depression and anxiety among the sample of Palestinian youth $(n=2481)$ aged $15-24$ years, 2014

\begin{tabular}{|c|c|c|c|c|c|c|}
\hline \multirow[t]{2}{*}{ Variable } & \multicolumn{2}{|c|}{$\begin{array}{c}\text { Elevated global } \\
\text { distress symptoms (\%) }\end{array}$} & \multicolumn{2}{|c|}{$\begin{array}{l}\text { Elevated depression } \\
\text { symptoms (\%) }\end{array}$} & \multicolumn{2}{|c|}{$\begin{array}{l}\text { Elevated anxiety } \\
\text { symptoms (\%) }\end{array}$} \\
\hline & No & Yes & No & Yes & No & Yes \\
\hline Being female & $38.4^{* * *}$ & $63.6^{* * *}$ & $36.5^{* * *}$ & $60.9^{* * *}$ & $41.5^{* * *}$ & $64.3^{* * *}$ \\
\hline Age & $18.7^{\star * *}$ & $19.4^{* * *}$ & $18.7^{* * *}$ & $19.4^{* * *}$ & $18.9^{* * *}$ & $19 \cdot 3^{* * *}$ \\
\hline Refugee & $25 \cdot 3$ & 26.7 & 24.1 & 27.4 & 25.8 & 26.1 \\
\hline Live in rural location & 70.1 & 71.7 & 69.1 & 72.2 & 70.1 & 72.1 \\
\hline Currently attending school & $65.0^{* *}$ & $59 \cdot 5^{* *}$ & $65.7^{* *}$ & $59.9^{* *}$ & $64.3^{*}$ & $59.5^{*}$ \\
\hline Currently working & $19.9^{*}$ & $16.9^{*}$ & 20.1 & 17.3 & $20.2^{* *}$ & $15.7^{* *}$ \\
\hline Wealth (asset) index & 0.005 & -0.005 & 0.011 & -0.009 & 0.011 & -0.018 \\
\hline Married or engaged & $13.8^{* * *}$ & $20.8^{* * *}$ & $14.2^{* *}$ & $19 \cdot 3^{* *}$ & $14.5^{* * *}$ & $21.4^{* * *}$ \\
\hline Very religious & 20.8 & 18.4 & $21.4^{*}$ & $18.3^{*}$ & $21.0^{*}$ & $17 \cdot 4^{*}$ \\
\hline Father is alive & $95 \cdot 6^{* * *}$ & $91.5^{* * *}$ & $95.6^{* *}$ & $92.2^{* *}$ & $95.2^{* * *}$ & $91.3^{* * *}$ \\
\hline Mother is alive & $99.3^{* * *}$ & $97 \cdot 5^{* * *}$ & $99.2^{* *}$ & $97.9^{* *}$ & $99.2^{* * *}$ & $97.3^{* * *}$ \\
\hline Has someone to turn to for support & 83.4 & 82.8 & 82.8 & 83.4 & 16.9 & 16.7 \\
\hline Fatalism & $2.00^{* * *}$ & $2.08^{* * *}$ & $1.98^{* * *}$ & $2.08^{* * *}$ & $2.01^{* *}$ & $2.08^{* *}$ \\
\hline Chance of having a good job by age 30 years & $51.1^{* * *}$ & $44 \cdot 9^{* * *}$ & $50.9^{* * *}$ & $46.2^{* * *}$ & $50.4^{* * *}$ & $44.7^{* * *}$ \\
\hline Currently using tobacco & 73.4 & 75.0 & 74.2 & 74.1 & 73.0 & 76.1 \\
\hline Has ever used alcohol & $7 \cdot 7^{* * *}$ & $14.0^{* * *}$ & $7 \cdot 3^{* * *}$ & $13.2^{* * *}$ & $8.4^{* * *}$ & $14.2^{* * *}$ \\
\hline Politically active & $21.9^{* * *}$ & $29.2^{* * *}$ & $21.0^{* * *}$ & $28.6^{* * *}$ & $22.6^{* * *}$ & $29.6^{* * *}$ \\
\hline Sum of violence event exposure & $2.56^{* * *}$ & $3.24^{* * *}$ & $2.45^{* * *}$ & $3.22^{* * *}$ & $2.64^{* * *}$ & $3.27^{* * *}$ \\
\hline Any violence exposure & $81.1^{* * *}$ & $89.6^{* * *}$ & $80.2^{* * *}$ & $88.9^{* * *}$ & $82.3^{* * *}$ & $89.5^{* * *}$ \\
\hline Any personally experienced violence & $42.4^{* * *}$ & $51.9^{* * *}$ & $40.9^{* * *}$ & $51.5^{* * *}$ & $42.8^{* * *}$ & $53 \cdot 3^{* * *}$ \\
\hline Any witnessed violence & $66.9^{* * *}$ & $75 \cdot 4^{* * *}$ & $65 \cdot 3^{* * *}$ & $75.2^{* * *}$ & $68.1^{* * *}$ & $75 \cdot 4^{* * *}$ \\
\hline Any vicarious violence & $63.5^{* * *}$ & $75 \cdot 4^{* * *}$ & $61.6^{* * *}$ & $74.9^{* * *}$ & $65.7^{* * *}$ & $74.5^{* * *}$ \\
\hline
\end{tabular}

Test for association of covariate and elevated symptomology of global distress, depression and anxiety was performed using chi squared test or 2-tailed independent t-test.

${ }^{*} \mathrm{P}<0.05,{ }^{* *} \mathrm{P}<0.01,{ }^{* * *} \mathrm{P}<0.001$.

\section{Data analysis}

Bivariate statistics (2-tailed, independent t-tests and chi squared tests) were used to examine correlates of the 3 measures of elevated psychiatric symptomatology (global distress, depression, anxiety). Next, logistic regression analyses examined multivariable correlates of these 3 mental health measures, controlling for bivariate correlates at the significance level of $P<0.05$. The analysis was done using STATA, version 13, applying the "Survey" routine, which incorporates the survey design, including the correlations of standard errors within sample clusters.

\section{Results}

\section{Sample descriptives}

Table 1 lists the demographic and background characteristics of the whole sample of 2481 participants, and by sex (1240 females, 1241 males). Mean age was 19.1 years, $18.5 \%$ were employed, $63.0 \%$ were attending school, $17.0 \%$ were married (substantially higher for females than males) and $26.0 \%$ were refugees, i.e. descendants of individuals who had lost land or livelihood during the 1948 or 1967 conflicts. Most refugee families do not actually live in refugee camps, which can be rural or urban.

\section{Elevated psychiatric symptomatology and violence exposure}

About half of the overall sample had elevated symptoms of global distress (45.7\%) and depression (55.2\%), and over one-third $(37.0 \%)$ had elevated symptoms of anxiety, but all rates were significantly higher among females than males (Table 1). Depression and anxiety were strongly related, with a correlation of the mean scores of $0.73(P$ $<0.001)$.

A high level of violence exposure was also observed in the sample: $85.0 \%$ of youth experienced at least 1 event in their lifetime, with a mean of $2.9(S D=2.1$; median $=$ 3) events experienced. The mean number of events experienced in the past year alone was $0.95(S D=1.29$; median $=1) ; 46.7 \%$ had been a victim of any personal violence event, $70.8 \%$ had witnessed any violence event perpetrated on a relative or close friend, and $68.9 \%$ had heard about any violence event experienced by a relative or close friend (Table 1). The most common personally experienced violence was being beaten up or assaulted by someone other than a policeman or soldier $(36 \%)$, while $12 \%$ report being beaten up or assaulted by police and $12 \%$ report being imprisoned or held by police. The most common witnessed violence was seeing a relative/friend 


\begin{tabular}{|c|c|c|c|c|c|c|}
\hline \multirow[t]{2}{*}{ Variable } & \multicolumn{2}{|c|}{ Elevated global distress } & \multicolumn{2}{|c|}{ Elevated depression } & \multicolumn{2}{|c|}{ Elevated anxiety } \\
\hline & $\begin{array}{c}\text { Model } 1 \\
\text { OR (95\% CI) }\end{array}$ & $\begin{array}{c}\text { Model 2 } \\
\text { OR (95\% CI) }\end{array}$ & $\begin{array}{c}\text { Model } 1 \\
\text { OR (95\% CI) }\end{array}$ & $\begin{array}{c}\text { Model 2 } \\
\text { OR (95\% CI) }\end{array}$ & $\begin{array}{c}\text { Model } 1 \\
\text { OR (95\% CI) }\end{array}$ & $\begin{array}{c}\text { Model } 2 \\
\text { OR (95\% CI) }\end{array}$ \\
\hline Being female & $3.3(2.6,4.2)^{* *}$ & $4.1(3.1,5 \cdot 3)^{* *}$ & $3.5(2.8,4.4)^{* *}$ & $4.4(3.5,5 \cdot 5)^{\star *}$ & $2.8(2.2,3.5)^{* *}$ & $3 \cdot 3(2 \cdot 7,4 \cdot 2)^{* *}$ \\
\hline Mean age & $1.1(1.0,1.1)^{* *}$ & $1.1(1.0,1.1)^{* *}$ & $1.1(1.0,1.1)^{* *}$ & $1.1(1.0,1.1)^{* *}$ & $1.0(1.0,1.0)$ & $1.0(1.0,1.1)$ \\
\hline Currently attending school & $1.0(0.8,1.3)$ & $1.0(0.8,1.3)$ & $0.9(0.7,1.1)$ & $0.9(0.7,1.2)$ & $0.8(0.6,1.1)$ & $0.9(0.7,1.2)$ \\
\hline Currently working & $0.9(0.7,1.2)$ & $0.9(0.7,1.2)$ & - & - & $0.8(0.6,1.1)$ & $0.8(0.6,1.1)$ \\
\hline Married or engaged & $0.8(0.6,1.0)^{*}$ & $0.7(0.6,1.0)^{*}$ & $0.6(0.5,0.8)^{* *}$ & $0.6(0.5,0.8)^{* *}$ & $0.9(0.7,1.2)$ & $0.9(0.7,1.2)$ \\
\hline Very religious & - & - & $0.9(0.8,1.2)$ & $0.9(0.8,1.2)$ & $0.9(0.7,1.1)$ & $0.9(0.7,1.1)$ \\
\hline Father is alive & $0.6(0.4,0.8)^{* *}$ & $0.6(0.4,0.8)^{* *}$ & $0.6(0.4,0.9)^{*}$ & $0.6(0.4,0.9)^{*}$ & $0.6(0.4,0.8)^{* *}$ & $0.6(0.4,0.8)^{* *}$ \\
\hline Mother is alive & $0.5(0.2,1.0)$ & $0.5(0.2,1.1)$ & $0.6(0.3,1.2)$ & $0.6(0.3,1.3)$ & $0.5(0.2,0.9)^{*}$ & $0.5(0.2,1.0)$ \\
\hline Fatalism & $1.1(0.9,1.3)$ & $1.1(0.9,1.3)$ & $1.3(1.1,1.5)^{* *}$ & $1.2(1.1,1.5)^{*}$ & $1.1(0.9,1.3)$ & $1.1(0.9,1.3)$ \\
\hline$\%$ chance of having a good job by age 30 & $1.0(1.0,1.0)^{* *}$ & $1.0(1.0,1.0)^{*}$ & $1.0(1.0,1.0)$ & $1.0(1.0,1.0)$ & $1.0(1.0,1.0)^{*}$ & $1.0(1.0,1.0)$ \\
\hline Has ever used alcohol & $2.2(1.7,2.9)^{* *}$ & $2.0(1.5,2.7)^{* *}$ & $2.0(1.5,2.7)^{* *}$ & $1.8(1.4,2.5)^{* *}$ & $2.1(1.5,2.8)^{* *}$ & $1.9(1.4,2.5)^{* *}$ \\
\hline Politically active & $1.5(1.2,1.8)^{* *}$ & $1.3(1.1,1.6)^{*}$ & $1.5(1.2,1.8)^{* *}$ & $1.3(1.1,1.6)^{*}$ & $1.5(1.2,1.8)^{* *}$ & $1.3(1.1,1.6)^{*}$ \\
\hline Overall violence exposure & $2.3(1.8,3.0)^{* *}$ & & $2.3(1.8,2.9)^{* *}$ & - & $2.1(1.6,2.8)^{* *}$ & - \\
\hline Personally experienced violence & - & $1.8(1.4,2.2)^{* *}$ & - & $1.8(1.5,2.2)^{* *}$ & - & $1.8(1.5,2.2)^{* *}$ \\
\hline Witnessed violence & - & $1.4(1.1,1.7)^{*}$ & - & $1.4(1.2,1.8)^{* *}$ & - & $1.3(1.0,1.7)^{*}$ \\
\hline Vicarious violence & - & $1.4(1.2,1.8)^{* *}$ & - & $1.5(1.2,1.9)^{* *}$ & - & $1.2(1.0,1.5)$ \\
\hline
\end{tabular}

$\mathrm{OR}=$ odds ratio $; \mathrm{CI}=$ confidence interval.

being beaten (58\%) or witnessing a relative/friend being shot (35\%). Regarding vicarious violence events, $60 \%$ had heard of a relative/friend being imprisoned and $35 \%$ had heard of a relative/friend being killed. Male youth reported exposure to more events of violence overall, as well as a greater proportion having experienced each of the 3 types of violence events, compared with females.

\section{Relationships between mental health and violence exposure}

Elevated symptoms of global distress, depression and anxiety were each significantly associated in bivariate analysis with the sum of violence exposure events, with exposure to any of the 3 types of violence events, and with a number of other variables (Table 2). Table 3 presents multiple logistic regressions exploring these relationships. First, using any violence exposure event experienced (across all types of violence exposure) as the sole violence independent variable and including other significant bivariate correlates of elevated global distress as controls (Model 1), violence exposure remains independently associated with elevated global distress. In models using 3 variables representing any experience of the 3 types of violence events (personally experienced, witnessed, vicarious) in place of overall violence exposure (Model 2), each of these exposure vari- ables was independently correlated with elevated global distress. Regressions predicting elevated depression and anxiety were similar, with the exception that experience of vicarious violence exposure was unrelated to elevated anxiety (Table 3).

Among other independent variables in the models, being female was associated with all 3 measures of elevated symptomatology, while being married or engaged was associated with lower odds of elevated global distress and depression (a reversal of the direction of the relationships observed in the bivariate analysis). Factors associated with elevated symptomology included the death of one's father, any history of alcohol use, greater fatalism (associated with elevated depression only), and lower expectations of having a good job by the age of 30 (global distress only).

Similar results were observed in separate regressions for male and female youth, with a few exceptions: among males, witnessed violence exposure and father's death were not independently associated with any of the 3 elevated psychiatric symptomatology measures; among females, being married or engaged, fatalism, older age, and expectations of having a good job were all unrelated to any of the elevated symptomatology measures (full results from these gender-specific analyses are available as supplementary data online). 


\section{Discussion}

In this rare, population-based sample of Palestinian youth, high levels of mental health problems were reported, with about half of the sample reporting elevated symptoms of global distress and depression, and onethird reporting elevated anxiety symptoms. Furthermore, nearly half the sample had personally been the victim of violence, and over two-thirds had ever witnessed or heard about violence being perpetrated on a close friend or relative. It should be noted that while much of the reported violence exposure was likely related to the Occupation and conflict, much of it was not, at least not directly. For example, as indicated, the most common personal experience of violence was being beaten by someone other than a soldier or policeman. This is consistent with findings from the sample of high rates of engagement of youth in physical fights with others (18).

Violence exposure was associated with each of the 3 forms of elevated psychopathology (global distress, depression, anxiety), and these mental health measures were associated with each of the 3 types of violence exposure (personally experienced, witnessed, and vicariously heard about). Significantly, these findings suggest that violence does not have to be personally experienced to influence mental health; indirect forms of violence exposure (e.g. witnessed and vicarious exposure) were also independently associated with mental health symptoms. This is consistent with other studies of youth exposure to community violence that were not conducted in conflict settings (5).

Consistent with studies in other environments $(4,14)$, gender differences were observed with regard to both mental health and violence exposure. Female youth reported significantly higher levels of mental health problems, while males reported higher exposure to violence overall and were more likely to have experienced each of the 3 types of violence events. The greater experience of violence among males may reflect gender differences in the contexts into which individuals can, or are willing to, enter, especially in a conservative environment where young females may experience family or social constraints on their movement and young men more often participate in political demonstrations. Additionally, it has been observed that in the face of occupation and conflict, Palestinian society has become more conservative and religious over the last several decades, which likely further dampens young women's independence and mobility (24). Being female was an independent correlate of higher odds of elevated symptoms of global distress, depression and anxiety, suggesting that factors independent of violence exposure contribute to Palestinian female youth experiencing higher levels of depression, anxiety and distress.

Among female youth, all 3 types of violence exposure were associated with elevated psychiatric symptomatology, and the magnitude of the relationship to symptomatology (odds ratio) was similar across each type of violence. In contrast, among males, having personally experienced violence had the strongest effects: odds ratios for global distress, depression and anxiety were at least descriptively higher for personal experience than for vicarious exposure; and witnessed violence exposure was not associated with any of the 3 mental health measures. With male youth being exposed to more violence, they may have a higher threshold for violence contributing to emotional distress, or violence may be normalized in their day-to-day lives, resulting in direct victimization being what is needed to cross this threshold.

Our analysis sought to identify factors in addition to violence exposure that either protect against mental health problems or are risk factors. The regression analysis revealed that for young men, being married or engaged reduced the likelihood of elevated symptoms of distress or depression. The social support that comes from a partner within a committed relationship may be instrumental to psychological well-being and positive coping with a stressful environment. This protective function was not evident among female participants, consistent with other research showing that being married is protective against depression more so for men than women (25). This may reflect gender differences in the demands and stress within marriage and power differentials between men and women in relationships in the Palestinian cultural context. For female youth, a different source of support, having a father who was still alive, was independently associated with lower odds of elevated psychiatric symptomatology, suggesting that family and parents specifically can provide vital sources of support for managing stress $(3,7)$.

Current alcohol use, reported by only $11 \%$ of the sample (18), was associated with elevated symptoms of distress, depression and anxiety, which is consistent with evidence demonstrating the comorbidity of substance use and mental health problems (26), including among youth in the Middle East (27). Substance use can be a signal of struggles in coping with stress, and this may be particularly true with substances that are less culturally acceptable, which is the case for alcohol (as opposed to tobacco) in the Palestinian context.

Fatalistic attitudes and beliefs about life, and pessimism regarding one's future (as reflected in lower expectancy for having a good job by age 30) were both associated with elevated symptoms of depression and distress, particularly among males. These findings suggest that mental health among youth is influenced by expectations, outlook and locus of control regarding the future, and this may be particularly true in contexts that are characterized by ongoing exposure to violence. Youth programmes and services need to help their clients see merits in their future and opportunities for success-though this is undoubtedly very challenging given the significant stressors and environmental challenges that Palestinian youth face. However, it should be cautioned that the observed relationships 
may not be causal since expectations and outlook may well be conditioned by depression or distress.

Engagement in political activism was also independently associated with higher odds of elevated psychiatric symptomatology. Here too, the crosssectional nature of the study makes interpretation ambiguous since relationships may be bi-directional. Although experiences of political activity (including frustration with unachieved goals or witnessing violence during protests) may lead to distress, those suffering a greater emotional stress from the protracted conflict may also be more likely to participate in protests.

In addition to the cross-sectional design, the limitations of this study include the reliance on selfreporting of symptom rather than more rigorous clinical interviews to examine mental health status and the presence of psychiatric disorders. Social desirability bias may have influenced participant responses, particularly with regard to mental health problems and substance use, and local gender norms could result in there being a gender differential with regard to candour; for example, males may have been more comfortable disclosing substance use behaviour, and females being more comfortable disclosing symptoms of distress. Our analysis of factors contributing to mental health resilience was hampered by the absence of measures of factors that have been found to be associated with resilience among youth exposed to violence, such as parenting practices, school performance, and coping styles. However, the use of a rare large, representative youth sample does offer important insights into the proportion of, and factors influencing, the mental health of youth with a high exposure to conflict and violence.

In summary, elevated symptoms of depression and anxiety were common in this representative sample of Palestinian youth, as was exposure to violence (both direct and indirect), and violence exposure was independently associated with such symptomatology. Female youth were less exposed to violence, but more likely than their male counterparts to report elevated symptoms of distress, depression and anxiety. Although, as noted, gender differences in candour may be in play, it is also possible that males are more apt to normalize exposure to violence. Youth services in the Palestinian and other Middle East contexts can also be informed by our findings that identify the influences on, or correlates of, mental health such as parental death, alcohol use and outlook and expectations for one's future as these can serve to characterize youth who may be at greater risk for mental health problems and have greater need for support services. Both preventative and therapeutic services related to mental health challenges stemming from violence exposure are needed for youth, and our findings suggest that such services should incorporate mechanisms to enhance social support from family and sense of control over and hope for one's future.

Funding: The authors received a grant from the Eunice Kennedy Shriver National Institute of Child Health and Human Development to conduct this study.

Competing interests: None declared.

\section{Exposition à la violence et liens avec la santé mentale chez les jeunes Palestiniens Résumé}

Contexte : L'exposition à la violence est un facteur de risque significatif pour le développement de psychopathologies chez les jeunes. La recherche sur les conséquences de l'exposition des jeunes à la violence pour leur santé mentale s'est principalement concentrée sur l'état de stress post-traumatique. Cependant, un lien avec la dépression et l'anxiété a également été établi. Du fait de l'ancienneté du conflit israélo-palestinien, les jeunes Palestiniens sont susceptibles d'être exposés à divers types de violence.

Objectifs : Nous avons examiné la symptomatologie psychiatrique en lien avec les formes directes et indirectes d'exposition à la violence.

Méthodes : Une enquête auprès des ménages a été menée en 2014 dans un échantillon représentatif de 2481 jeunes Palestiniens. Les critères d'autoévaluation utilisés incluaient la symptomatologie psychiatrique (détresse générale, dépression, anxiété) et l'exposition à la violence (en tant que victime, témoin direct ou indirect).

Résultats : La proportion de symptômes aigus de détresse générale (46\%), de dépression (55\%) et d'anxiété (37\%) était élevée ; $47 \%$ des personnes interrogées avaient été personnellement victimes de violence, $71 \%$ avaient été témoins de violences et $69 \%$ avaient entendu le récit de violences subies par une personne proche. Dans l'analyse de régression logistique, l'élimination des autres corrélats bivariés, l'exposition à un acte de violence quelconque, ainsi que chacun des trois types de violence, ont été associés de manière indépendante à chacun des trois critères de symptomatologie psychiatrique aiguë. Les jeunes femmes étaient quatre fois plus nombreuses à signaler des psychopathologies aiguës, en dépit d'un risque moins élevé d'être confrontées à chaque type de violence.

Conclusions : Ces résultats suggèrent la nécessité de mettre en place des services répondant aux besoins des jeunes en matière de santé mentale dans un contexte les exposant fortement à la violence. Ils indiquent aussi que des stratégies sexospécifiques pourraient être utiles. 


\section{التعرض للعنف وعالة ذلك بالصحة النفسية للشباب الفلسطيني \\ جلين واجنير، بيتر جليك، أمية الخماش، محمد شاهين، ريان براون، بروديومنا جوتام، ريتا كرم، سيباستيان لينماير، سلوى مسعد}

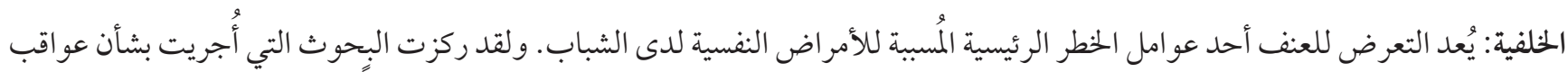

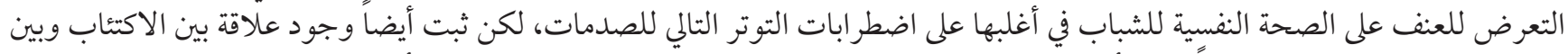

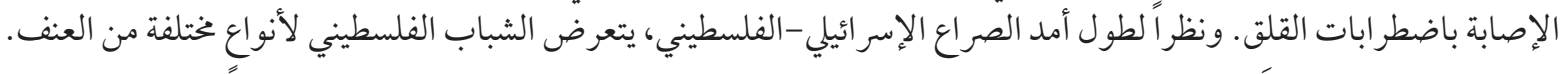
الأهداف: لقد فحصنا الأَعْر اض النفسية وعلاقتها بالتعرض لصور العنف المختلفة بطريقة مباشرة أو غير مباشرة.

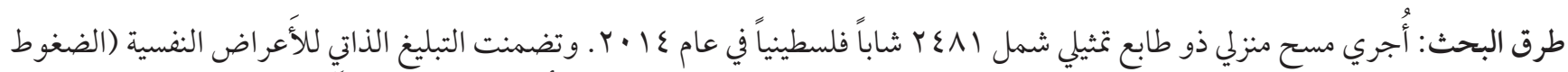

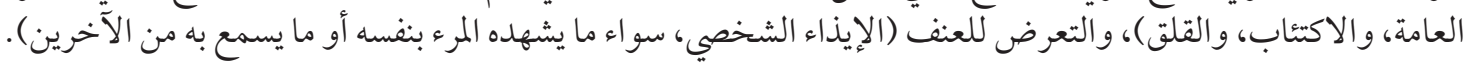

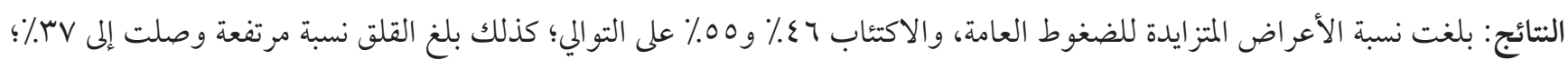

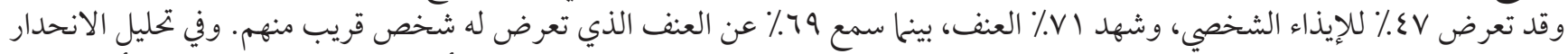

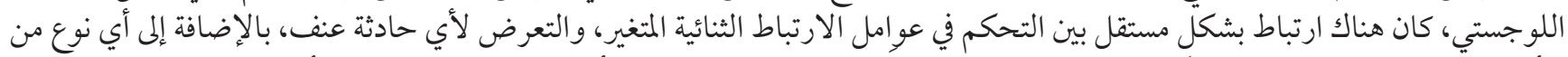

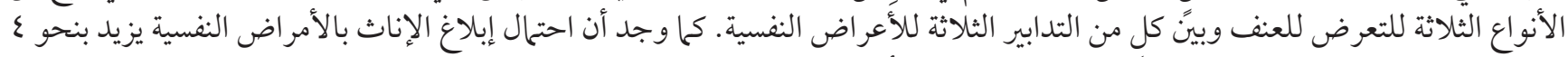

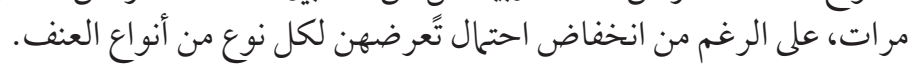

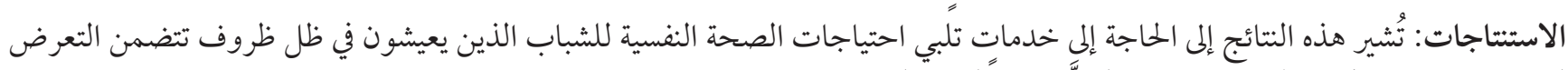

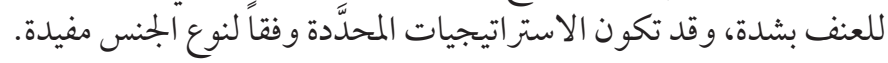

\section{References}

1. Trickett PK, Durán L, Horn JL. Community violence as it affects child development: issues of definition. Clin Child Fam Psychol Rev. 2003 Dec;6(4):223-36. PMID:14719635

2. Dubow EF, Boxer P, Huesmann LR, Shikaki K, Landau S, Gvirsman SD, et al. Exposure to conflict and violence across contexts: relations to adjustment among Palestinian children. J Clin Child Adolesc Psychol. 2010;39(1):103-16. doi:10.1080/15374410903401153

3. Barber BK. Annual research review: the experience of youth with political conflict-challenging notions of resilience and encouraging research refinement. J Child Psychol Psychiatry. 2013 Apr;54(4):461-73. doi:10.1111/jcpp.12056

4. Mrug S, Loosier PS, Windle M. Violence exposure across multiple contexts: individual and joint effects on adjustment. Am J Orthopsychiatry. 2008 Jan;78(1):70-84. doi:10.1037/0002-9432.78.1.70

5. Fowler PJ, Tompsett CJ, Braciszewski JM, Jacques-Tiura AJ, Baltes BB. Community violence: a meta-analysis on the effect of exposure and mental health outcomes of children and adolescents. Dev Psychopathol. 2009 Winter;21(1):227-59. doi:10.1017/ So954579409000145

6. Singer MI, Miller DB, Guo S, Flannery DJ, Frierson T, Slovak K. Contributors to violent behavior among elementary and middle school children. Pediatrics. 1999 Oct 1;104(4):878-84. doi:10.1542/peds.104.4.878

7. Dubow EF, Huesmann LR, Boxer P, Landau S, Dvir S, Shikaki K, et al. Exposure to political conflict and violence and posttraumatic stress in Middle East youth: Protective factors. J Clin Child Adolesc Psychol. 2012;41(4):402-16. doi:10.1080/15374416.2012.6 84274

8. Thabet AA, Abed Y, Vostanis P. Comorbidity of PTSD and depression among refugee children during war conflict. J Child Psychol Psychiatry. 2004 Mar 1;45(3):533-42. PMID:15055372

9. Abdeen Z, Qasrawi R, Nabil S, Shaheen M. Psychological reactions to Israeli occupation: Findings from the national study of school-based screening in Palestine. Int J Behavioral Development. 2008 Jul;32(4):290-7. https://doi. org/10.1177/0165025408092220

10. Massad S, Javier Nieto F, Palta M, Smith M, Clark R, et al. Mental health of children in Palestinian kindergartens: resilience and vulnerability. BMC Public Health. 2012 Jan 11;12:27. doi:10.1186/1471-2458-12-27

11. Barber BK, Schluterman JM. An overview of the empirical literature on adolescents and political violence. In: Barber BK, ed. Adolescents and war: how youth deal with political violence. New York: Oxford University Press; 2009.

12. Rutter M. Psychosocial resilience and protective mechanisms. Am J Orthopsychiatry. 1987 Jul;57(3):316-331. doi: 10.1111/j.19390025.1987.tbo3541.x

13. Weems CF, Overstreet S. An ecological-needs-based perspective of adolescent and youth emotional development in the context of disaster: Lessons from Hurricane Katrina. In: Cherry KE, ed. Natural disasters from a life span developmental perspective: an introduction. Baton Rouge: Springer; 2009:27-44. 
14. Zona K, Milan S. Gender differences in the longitudinal impact of exposure to violence on mental health in urban youth. J Youth Adolesc. 2011 Dec;40(12):1674-90. doi: 10.1007/s10964-011-9649-3

15. Foster JD, Kuperminc GP, Price AW. Gender differences in posttraumatic stress and related symptoms among inner-city minority youth exposed to community violence. J Youth Adolesc. 2004 Feb 1;33(1):59-69.

16. Fragmented lives - humanitarian overview 2016, occupied Palestinian territory. Jerusalem: United Nations Office for the Coordination of Humanitarian Affairs; 2017 (http://new.ochaopt.org/sites/default/files/fragmented_lives_2016_english.pdf, accessed 12 July 2019).

17. Israel/Palestine: events of 2016. New York; Human Rights Watch. (https://www.hrw.org/world-report/2017/country-chapters/ israel/palestine, accessed 12 July 2019).

18. Glick P, Kammash U, Shaheen M, Brown RA, Goutam P, Karam R, et al. Health risk behaviours of Palestinian youth: findings from a representative survey. East Mediterr Health J. 2018;24:127-36. PMID:29748941

19. Sahn DE, Stifel D. Exploring alternative measures of welfare in the absence of expenditure data. Review of Income and Wealth. 2003 Dec 1;49(4):463-89. https://doi.org/10.1111/j.0034-6586.2003.00100.x

20. Derogatis LR, Lipman RS, Rickels K, Uhlenhuth EH, Covi L. The Hopkins Symptom Checklist (HSCL). A measure of primary symptom dimensions. Mod Prob Pharmacopsychiatry. 1974;7:79-110. PMID:4607278

21. Batterham PJ, Sunderland M, Slade T, Calear AL, Carragher N. Assessing distress in the community: psychometric properties and crosswalk comparison of eight measures of psychological distress. Psychol Med. 2018 Jun;48(8):1316-24. doi:10.1017/ So033291717002835

22. Halepota AA, Wasif SA. Hopkins Symptoms Checklist 25 (HSCL-25) Urdu translation: an instrument for detecting anxiety and depression in torture and trauma victims. J Pak Med Assoc. 2001 Jul;51(7):255-7. PMID:11558218

23. Esparza OA, Wiebe JS, Quiñones J. Simultaneous development of a multidimensional fatalism measure in English and Spanish. Curr Psychol. 2015 Dec 1;34(4):597-612. doi:10.1007/s12144-014-9272-z

24. 2016-2021 Gender Advocacy Strategy. Ramalllah: Sharek Youth Forum; 2016 (http://sharek.ps/attachment/13/Final_Gender\%20 Advocacy\%20Strategy\%20(sm).compressed.pdf, accessed 12 July 2019).

25. Scott KM, Wells JE, Angermeyer M, Brugha TS, Bromet E, Demyttenaere K, et al. Gender and the relationship between marital status and first onset of mood, anxiety and substance use disorders. Psychol Med. 2010 Sep;40(9):1495-505. doi: 10.1017/ So033291709991942

26. Chan YF, Dennis ML, Funk RR. Prevalence and comorbidity of major internalizing and externalizing problems among adolescents and adults presenting to substance abuse treatment. J Subst Abuse Treat. 2008 Jan 31;34(1):14-24. doi:10.1016/j. jsat.2006.12.031

27. Ismayilova L, Hmoud O, Alkhasawneh E, Shaw S, El-Bassel N. Depressive symptoms among Jordanian youth: results of a national survey. Community Ment Health J. 2013 Feb;49(1):133-40. doi:10.1007/s10597-012-9529-7 